\title{
Comparison of different models for assessing air quality in Krasnoyarsk using satellite data
}

\author{
Konstantin Krasnoshchekov ${ }^{1, *}$, Oleg Yakubailik ${ }^{2}$ \\ ${ }^{1}$ FRC KSC SB RAS, Krasnoyarsk, Russia \\ ${ }^{2}$ Institute of Computational Modeling SB RAS, Krasnoyarsk, Russia
}

\begin{abstract}
Methods for estimating the atmospheric pollution of Krasnoyarsk by particulate matter based on satellite data on the aerosol optical depth (AOD) are considered. Satellite data from the MODIS MAIAC algorithm with a spatial resolution of $1 \mathrm{~km}$ are used together with data from the ground-based $\mathrm{PM}_{2.5}$ environmental monitoring stations of the FRC KSC SB RAS research network. A comparative analysis of the relationship between the calculated values of $\mathrm{PM}_{2.5}$ obtained from AOD data and groundbased measurements of $\mathrm{PM}_{2.5}$ in the summer of 2019 is presented. Various models of the relationship between these parameters were investigated, and a high level of correlation of these values was obtained. The calculated coefficient of determination was about 0.7 .
\end{abstract}

\section{Introduction}

Numerous epidemiological studies show that there is a relationship between the concentrations of particulate matter (PM - particulate matter) in the atmosphere and public health [1-2]. Attention to this issue is constantly increasing, with PM monitoring networks being established in many cities. Monitoring stations usually measure the concentration of three types of particulate matter $\left(\mathrm{PM}_{10}, \mathrm{PM}_{2.5}, \mathrm{PM}_{1}\right.$ - particles of different sizes). $\mathrm{PM}_{2.5}$ is considered the most dangerous for human health, since the particle size up to 2.5 microns allows them to enter the human bloodstream through breathing and lead to various diseases.

PM monitoring is based primarily on ground measurements. Networks of monitoring stations have been established today in many cities, but the number of observation points in them, as a rule, is small, these point measurements do not provide detailed information on the spatial characteristics and the distribution of PM in urban areas of interest. The time span for on-site PM measurements also varies greatly depending on the period of operation of the instrument and its functionality. These reasons determine the development of works on PM assessment by satellite remote sensing methods.

The AOD parameter (aerosol optical depth) is a value that characterizes the attenuation of sunlight as it passes through the atmosphere. Particulate matter in the atmosphere (dust, smoke, pollution) absorbs or scatters light. The AOD value depends on the amount of particulate matter that prevents direct sunlight from reaching the ground. This is a dimensionless number that is related to the amount of PM in the vertical column of the

\footnotetext{
* Corresponding author: krasko@icm.krasn.ru
} 
atmosphere above the observation site. Numerous linear [3], chemical [4], transport [5] and neural [6] models have been developed to determine how AOD correlates with ground-based PM measurements. However, the size distribution of particles, their composition, air humidity, and wind speed significantly reduce the value of the AOD-PM correlation [6].

\section{Data and measurement}

\subsection{Study area}

The city of Krasnoyarsk is actively developing and currently has an area of about $350 \mathrm{~km}^{2}$. It is located in a river valley, stretching $20-25 \mathrm{~km}$ along the river and 3-4 km inland, abutting the mountain ranges that frame the valley. The city lies as if in a bowl, at the bottom of which a river flows. These features of the relief, which form the ecological environment of the city, determine the circulation of air masses and the low scattering power of the atmosphere, which leads to the accumulation of pollutants in the city and suburban areas. From the south and west of the city there are forests and hilly terrain, from the north and east the relief is predominantly flat. Like all major cities in the world, Krasnoyarsk is subject to negative impact on the environmental situation. Its deterioration is facilitated by the fact that the city is the largest transport hub in Eastern Siberia; the presence of a number of large enterprises in the metallurgical, engineering and chemical industries aggravates the situation. It is shown in [7] that the concentration of $\mathrm{PM}_{2.5}$ in Krasnoyarsk is $64 \%$ higher than the average for Russia.

\subsection{Satellite observation of $\mathrm{PM}_{2.5}$}

The study of the parameters of aerosols in the atmosphere using specially developed methods and technologies for processing Earth remote sensing data are devoted to many works. Since the launch of the Terra and Aqua satellites about 20 years ago, algorithms have been proposed for obtaining AOD with a spatial resolution of 10 and $3 \mathrm{~km}$ per pixel. Later, the method of interpreting the recorded data was improved, algorithms with a higher spatial resolution $(1 \mathrm{~km})$ were proposed.

In the course of our work, we used AOD data with a spatial resolution of $1 \mathrm{~km}$, measured using a MODIS spectrophotometer, MAIAC algorithm, product MCD19A2. The MCD19A2 product contains data from the MODIS spectrophotometer installed on the Terra and Aqua satellites. This product was published on May 30, 2018 and contains AOD data since February 1, 2000. MAIAC provides a uniform $1 \mathrm{~km}$ grid resolution in the selected projection regardless of the scan angle. MAIAC data has limitations in obtaining information about AOD. There should be no clouds over the area, it should not be covered with snow. Consequently, data on AOD in winter for Krasnoyarsk are not available.

\subsection{Ground-based observations of $\mathrm{PM}_{2.5}$}

The research monitoring network of the Federal Research Center "Krasnoyarsk Science Center of the Siberian Branch of the Russian Academy of Sciences" (FRC KSC SB RAS) was selected as the information source for the ground-based measurements of $\mathrm{PM}_{2.5}$. In total, data from 13 monitoring stations were used. The FRC monitoring network was deployed in the fall of 2018 .

In our study, we used $\mathrm{PM}_{2.5}$ measurements from the FRC posts and AOD measurements for the period from June to August 2019. The choice of this time range is due to several factors. First, for summertime data, it is possible to compare ground-based and satellite 
measurements, which is the subject of research in this work. Second, a preliminary analysis of the data showed that at the indicated time, there were significant variations in air pollution in the city associated with the short-term but strong impact of forest fires in the vicinity of the city. We studied the relationship between AOD and $\mathrm{PM}_{2.5}$ concentrations on the Krasnoyarsk city scale. The location of $\mathrm{PM}_{2.5}$ ground-monitoring stations is shown in Fig. 1.

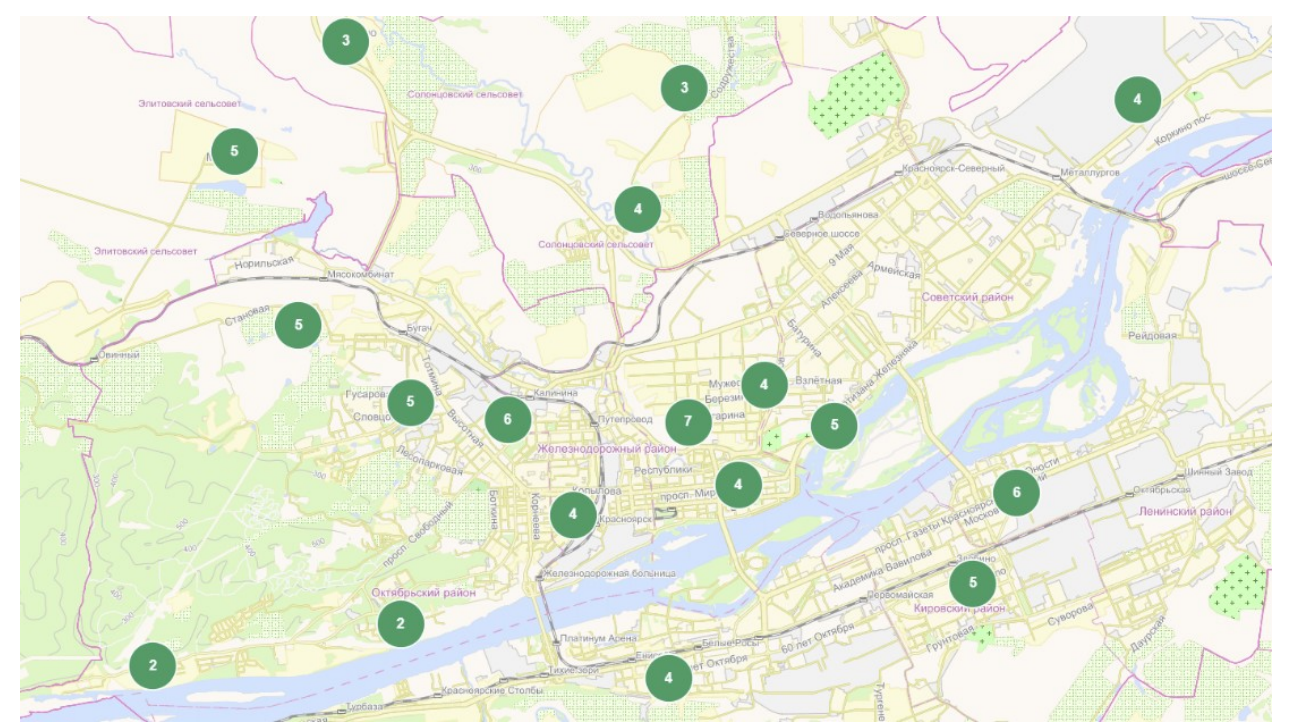

Fig. 1. Location of monitoring stations of KSC.

The green circle marks the location of monitoring stations in the city of Krasnoyarsk as of October 2020. Their distribution throughout the city is relatively uniform, but taking into account the features and inhomogeneities of the relief. A sufficient number of ground-based monitoring stations allows one to obtain comparable results with the MODIS MAIAC satellite data used in this work.

It is worth paying special attention to the timing of measurements of ground data. The city monitoring system takes measurements continuously, with a time step of several minutes. At the same time, analysis of the data shows that due to changes in meteorological conditions (for example, wind speed and direction), the situation with city pollution can radically change in a few hours. Therefore, in the framework of this study, we used data averaged over time intervals corresponding to the time of image registration by the Terra and Aqua satellites.

\subsection{Meteorological observation}

Part of the meteorological information required for the calculations was obtained from $\mathrm{PM}_{2.5}$ ground monitoring stations (temperature and air humidity). The planetary boundary layer height (PBLH) parameter is derived from the NASA Global Forecast System (GFS) atmospheric model.

\section{5 $\mathrm{PM}_{2.5}$ estimation from satellite data}

This paper compares the calculated $\mathrm{PM}_{\text {calc }}$ data using a linear regression model that includes AOD values, formula (1) and an algorithm that includes AOD data, boundary layer heights, 
air humidity, aerosol gyroscopic growth coefficient (formula (2)) [8]. The calculated $\mathrm{PM}_{\text {calc }}$ results were compared with the values measured at ground monitoring stations.

The linear regression equation is

$$
P M_{\text {calc }}=a \cdot A O D+B
$$

where $a$ and $B$ are the linear regression coefficients and are equal to $7.2 \cdot 10^{-3}$ and $5.3 \cdot 10^{-3}$, respectively. The result obtained using the linear model is shown in Fig. 3.

However, the linear model does not take into account such parameters as air humidity $\mathrm{RH}$, boundary layer height PBLH) coefficient of gyroscopic aerosol growth $\gamma$. Therefore, the spatial distribution of PM concentrations was estimated using the refined model:

$$
P M_{\text {calc }}=[A O D /(A \cdot P B L H)] /\left\{K \cdot\left[(1-R H) /\left(1-R H_{0}\right)\right]^{-\gamma}\right\}
$$

where AOD is the aerosol optical thickness data obtained by satellite methods; RH is the air humidity; PBLH is the height of the atmospheric boundary layer.

The result is shown in Fig. 3. PBLH was obtained from GFS data, RH parameter was measured using ground-based monitoring stations. The $\gamma$ and $\mathrm{K}$ values are aerosol characteristics and are derived from [8].

\section{Results and discussion}

Since satellite data for the territory of the city of Krasnoyarsk are not available in winter due to the presence of snow cover, and the network of ground monitoring stations was deployed in the fall of 2018, only the period from June to August 2019 was studied. The data of the MODIS MAIAC algorithm with a resolution of $1 \mathrm{~km}$ were used, since the spatial resolution is of great importance on a city scale. A comparison of this data with the less detailed MODIS MOD04 data $(10 \mathrm{~km})$ is shown in Fig. 2.
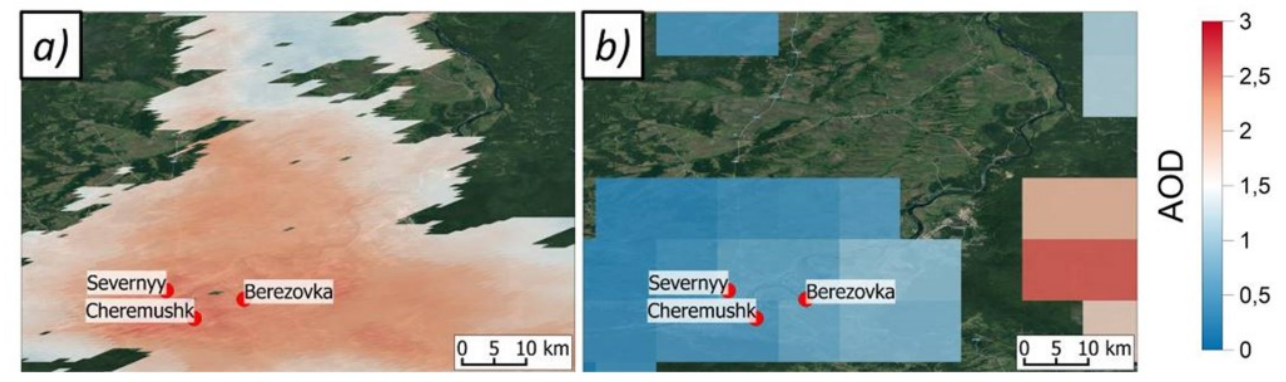

Fig. 2. AOD map for the territory of Krasnoyarsk with its surroundings. Data calculated using MODIS algorithms with a spatial resolution of $1 \mathrm{~km}$ (a) and $10 \mathrm{~km}(\mathrm{~b})$.

During the study period, not a single unfavorable weather conditions mode was introduced. However, the monitoring stations registered the excess maximum permissible concentration. The AOD values were taken over the location of ground monitoring posts, then they were averaged and the average value for the city was obtained. From the obtained value, the PM value was calculated using formulas 1 and 2 . The calculated $\mathrm{PM}_{\text {calc }}$ values were compared with the PM values, which were obtained as an average value from all monitoring posts, taken at 12:00 local time.

The result obtained using the linear model is shown in Fig. 3. The calculated $\mathrm{PM}_{\text {calc }}$ values using the linear model have a coefficient of determination equal to 0.73 . It follows that the 
PM data calculated using satellite monitoring have a high agreement with the data measured at ground-based monitoring stations.

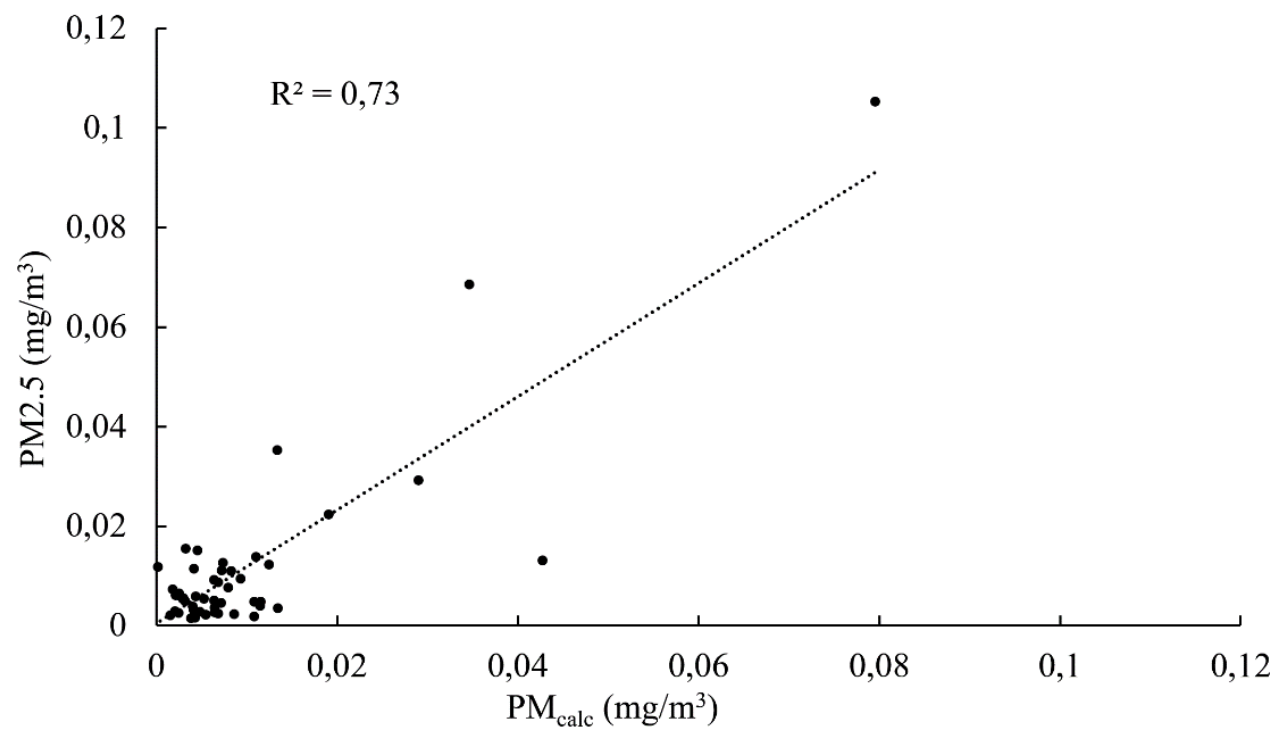

Fig. 3. Comparison of PM2.5 received from the posts of KSC and PM and calculated using a linear model $\left(\mathrm{PM}_{\text {calc }}\right)$.

Using formula 2 , we obtained a coefficient of determination of 0.67 , which indicates a fairly good fit with the ground-based $\mathrm{PM}_{2.5}$ data (Fig. 4).

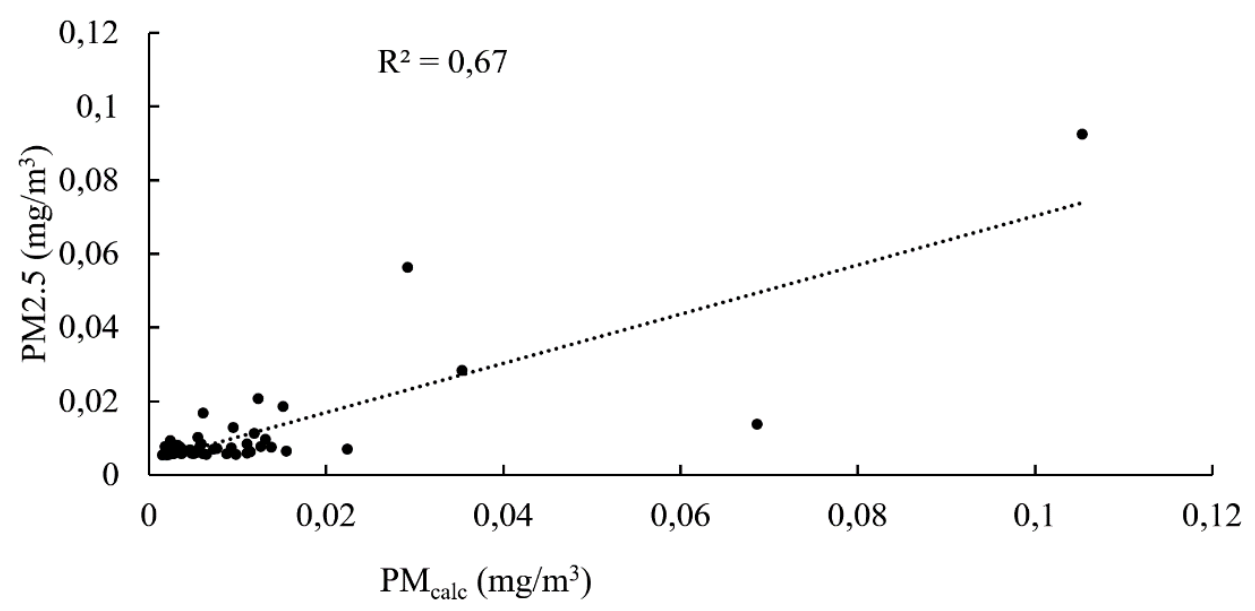

Fig. 4. Comparison of PM received from KSC posts and calculated values using remote sensing data

The results obtained using the linear regression model showed a higher correlation with ground-based observations when compared with the values obtained using the model described in [7]. However, in both cases, a sufficiently high correlation with ground-based data was obtained. Using data from environmental monitoring posts together with data of high spatial resolution MODIS MAIAC, it is possible to create a basis for improving the environmental situation of the city. 


\section{References}

1. Y.J. Kaufman, D. Tanré, O. Boucher, Nature 419, 6903, 215 (2002)

2. J. Schwartz, F. Laden, A. Zanobetti Environ. Health Perspect. 110, 10, 1025 (2002)

3. X.Q. Yap, M. Hashim ACP. 133517 (2013)

4. I. Kloog, F. Nordio, B. A. Coull, J. Schwartz, Environ. Sci. Technol 46, 21, 11913 (2012)

5. P. Gupta, S.A. Christopher J. of Geophysical Research 114, 14205 (2009)

6. J. Wang, S.A. Christopher Geophys. Res. Lett. 30, 21, 2095 (2003)

7. C. Lin, L.D. Labzovskii, H.W.L. Mak, J.C. Fung, A.K. Lau, S.T. Kenea, J. Ma Atmos. Environ. 117410 (2020)

8. C. Lin, Y. Li, Z. Yuan, A.K. Lau, C. Li, J.C. Fung Remote Sens. Environ 156, 117 (2015) 